\title{
Platelet Count/Splenic Diameter Ratio to Predict Oesophageal Varices in Portal Hypertension
}

\author{
Buddhi Sagar Lamichhane $^{1}$, Manoj Koirala ${ }^{1}$ and Bishwo Raj Baral ${ }^{1}$ \\ ${ }^{1}$ Department of Internal Medicine, Pokhara Academy of health sciences, Pokhara
}

\section{Correspondance:}

Buddhi Sagar Lamichhane, MD

Department of Internal Medicine,

Pokhara Academy of Health sciences,

Pokhara, Nepal

Email: buddhis1999@gmail.com

Article received : $13^{\text {th }}$ October, 2019

Article accepted : $16^{\text {th }}$ November, 2019

\section{ABSTRACT}

Background: One of the major causes of morbidity and mortality in Nepal is portal hypertension due to liver cirrhosis. In rural areas where a lot of cases of cirrhosis of liver are prevalent and endoscopic expertise and facilities are not available, predicting the presence of esophageal varices through noninvasive means may reduce a large number of unnecessary endoscopies. This study is to identify the relationship of platelet count /splenic bipolar diameter ratio with the presence of esophageal varices in portal hypertension. Materials and methods: Eighty patients were included in this study between Jestha 2072 to Baisakh 2073 with the diagnosis of portal hypertension admitted in Bir hospital,Kathmandu which is a tertiary hospital of government of Nepal, which were mostly due to liver cirrhosis. The patients fulfilling the inclusion criteria underwent lab investigations, ultra sonogram and UGI endoscopy. The data were assessed for descriptive studies and means were compared using t- test. The cut off value of platelet count to spleen diameter ratio of 1150 was used to predict the presence or absence of oesophageal varices. Statistical analysis was done using SPSS 20 software Results: Platelet count to splenic diameter ratio with a cut off value of 1150 has sensitivity of $89.7 \%$, specificity of $83.3 \%$, positive predictive value of $96.8 \%$ and negative predictive value of $58.8 \%(\mathrm{p}=$ $0.002, \mathrm{CI}=95 \%$ ) with $89.5 \%$ accuracy. Conclusion: Platelet count to splenic bipolar diameter ratio can be a good predictor of presence of esophageal varices in patients with portal hypertension in the resource poor settings. Keywords: Esophageal varices, platelet count, portal hypertension, splenic diameter

\section{INTRODUCTION}

Portal hypertension is the main complication of liver cirrhosis. ${ }^{1}$ More than $80 \%$ of cirrhotic patients develop esophageal varices (EVs) at some point, and $30 \%$ of these have at least one bleeding episode because of rupture of a varix., ${ }^{2,3}$ Most first bleeding episodes happen during the first year after the detection of the varices, with a $5 \%-10 \%$ mortality attributed to the initial hemorrhage. ${ }^{4}$ One of the major causes of morbidity and mortality in Nepal is liver cirrhosis though the exact burden of the disease is still not completely measured. Alcohol consumption is socially acceptable and seems to be the major cause of liver cirrhosis. A retrospective study done in 2008 in Liver unit of Bir hospital showed that chronic alcohol consumption related 
Liver Disease account for $38.5 \%$ of inpatients followed by viral hepatitis $33.8 \%{ }^{5}$

The grade of EVs often correlates with the severity of liver disease. While approximately $85 \%$ of individuals with Child-Turcotte Pugh (CTP) C cirrhosis have varices, they are present in only $45 \%$ in CTP A cirrhosis. ${ }^{6}$ Screening endoscopy in CTP A is recommended only in the presence of thrombocytopenia of $<140,000 / \mu 1$, portal vein diameter of more than $13 \mathrm{~mm}$ or Porto systemic collaterals on ultrasound examination, ${ }^{7}$ while screening endoscopy is advised in all patients of CTP B and C cirrhosis.

The first bleeding ends with mortality in about $30 \%$ cases. Out of this, $8 \%$ die during the first two days due to unrestrained bleeding, and the others die during six weeks from initial bleeding. The risk of repeated bleeding is highest in the first five days, and then it decreases gradually so that within six weeks it becomes equal with the risk for the first bleeding. ${ }^{8}$

In 1996, The American Association for the Study of Liver Disease stated that cirrhotic patients should be screened for the presence of esophageal varices when portal hypertension is diagnosed. However, this approach has two major limitations. Endoscopy is an invasive procedure and secondly the cost effectiveness of this approach is also questionable as only $9-36 \%$ patients with cirrhosis are found to have varices on screening endoscopy. It may be more cost-effective to routinely screen only patients at high risk for the presence of varices so as to reduce the increasing burden and procedure cost of endoscopy units. However, the factors that predict the presence of varices are not well defined. Identification of non-invasive predictors of esophageal varices will enable to carry out upper gastrointestinal (UGI) endoscopy in selected group of patients thus avoiding unnecessary intervention and at the same time not missing the patients at risk of bleeding. Also in rural areas in Nepal where a lot of cases of cirrhosis of liver are prevalent and endoscopic expertise and facilities are not available, platelet count to splenic diameter ratio can be used to detect cases at high risk of having varices and variceal bleeding. As earlier studies have demonstrated the relationship between platelet count to splenic diameter ratio and the presence of esophageal varices, we want to reconfirm these findings in our setting.

\section{MATERIALS AND METHODS}

It is a hospital based, cross sectional study conducted at Bir hospital ,Kathmandu, Nepal, which is a tertiary care hospital of government of Nepal, between Jestha 2072 to Baishakh 2073 to identify the relationship of platelet count /spleen bipolar diameter ratio with the presence of esophageal varices in portal hypertension. Study was approved by Institutional Review Board (IRB) of NAMS, Bir hospital. Eighty randomly selected cases with inclusion criteria were included in the study. Inclusion criteria were any patients more than 18 years diagnosed with portal hypertension based on clinical, biochemical and ultrasonography findings were enrolled. Portal hypertension was diagnosed on the basis of history and clinical examination, biochemical analysis, serum ascitic albumin gradient(SAAG) $\geq 1.1$, ultra sonogram showing portal vein diameter $\geq 13 \mathrm{~mm}$, splenic vein diameter $>10 \mathrm{~mm}$, splenic bipolar diameter $>11 \mathrm{~cm}$, liver echo texture, liver size, splenic size, portal systemic collaterals, portal vein obstruction, ascites. Patients who have already undergone endoscopic or surgical intervention for portal hypertension previously, Patients with evidence of HCC on ultrasonography, patients taking primary prophylaxis of variceal bleeding, Patients with portal hypertension who are unconscious, uncooperative, with recent MI, arrhythmias were excluded from the study.

Convenience sampling method was applied for the selection of samples. Samples were chosen from the patients of portal hypertension visiting the hospital (either admitted in the ward, OPD visits or Emergency visits) fulfilling the inclusion criteria.

Data were collected using a structured Performa covering the relevant details. . Investigations including $\mathrm{CBC}$, LFT, and PT/INR, serum total protein, albumin and ascitic fluid for albumin were performed.

Ultrasonography was done for all the patients under study either at the time of admission at emergency or after patient is admitted in the ward. Measurement of the liver echo texture, size, portal vein diameter, portal systemic collaterals, splenic vein diameter and splenic bipolar diameter were taken into account in addition to other findings of portal hypertension. The patient underwent upper gastrointestinal endoscopy after obtaining date from liver unit or gastroenterology to evaluate for presence and degree of esophageal varices using 
a video gastroscope without any medication. Endoscopy was performed by the trained endoscopist. The degree of esophageal varices was classified according to AASLD guideline as mentioned below.

Recommended grading according to AASLD guidelines: ${ }^{9}$

Small varices: $\leq 5 \mathrm{~mm}$

Large varices: $>5 \mathrm{~mm}$

Data were tabulated and stastical analysis was performed using SPSS version 20. The data were assessed for descriptive studies and means were compared using t- test. Best cut off value of platelet count to splenic diameter ratio for the prediction of presence of esophageal varices was determined by using ROC curve as 1150. Sensitivity, specificity, positive predictive value and negative predictive value were determined for platelet count to splenic diameter ratio cut off of 1150 . P-value of less than 0.05 is considered significant.

Variables

\section{USG evidence of splenomegaly}

Length of spleen was obtained at right lateral decubitus position in the coronal plane with long axis through the hilum. Spleen size more than 11 $\mathrm{cm}$ was taken as the cutoff length.

Platelet Count

The normal range of platelets was taken as 150-550 x $10^{9} /$ litre.

\section{RESULTS}

In this study, a total of 80 patients with portal hypertension visiting Bir Hospital, Mahabouddha, and Kathmandu in time period of one year were included. All had undergone series of lab investigations and evaluated according to the results of the investigations.

\section{Table 1: Age distribution}

\begin{tabular}{lcc}
\hline $\begin{array}{l}\text { Age (in } \\
\text { years) }\end{array}$ & Frequency $(\mathbf{n}=\mathbf{8 0})$ & Percentage (\%) \\
\hline $18-26$ & 4 & 5 \\
$30-39$ & 12 & 15 \\
$40-49$ & 29 & 36.30 \\
$50-59$ & 24 & 30.00 \\
$\geq 60$ & 11 & 13.90 \\
\hline
\end{tabular}

Table 2: Endoscopic findings

\begin{tabular}{lcc}
\hline $\begin{array}{l}\text { Esophageal } \\
\text { varices }\end{array}$ & $\begin{array}{c}\text { Frequency } \\
(\mathbf{n}=\mathbf{8 0})\end{array}$ & $\begin{array}{c}\text { Percentage } \\
(\mathbf{\%})\end{array}$ \\
\hline No varix & 12 & 15.0 \\
$\begin{array}{l}\text { Varices } \\
\text { present }\end{array}$ & 68 & 85 \\
\hline $\begin{array}{l}\text { The table 2 shows that } 85 \% \text { of the patients have } \\
\text { esophageal varices. }\end{array}$
\end{tabular}

Table 3: Esophageal varices with mean platelet count

\begin{tabular}{lcccc}
\hline $\begin{array}{l}\text { Esoph- } \\
\text { ageal } \\
\text { varices }\end{array}$ & $\begin{array}{l}\text { No of } \\
\text { patients }\end{array}$ & $\begin{array}{l}\text { Mean } \\
\text { platelet } \\
\text { count } \\
\left(/ \mathbf{m m}^{3}\right)\end{array}$ & $\begin{array}{l}\text { Standard } \\
\text { deviation }\end{array}$ & value \\
\hline Non & 12 & 236833 & 87797 & \\
$\begin{array}{l}\text { Varices } \\
\text { present }\end{array}$ & 68 & 97235 & 72001 & $<0.001$ \\
\hline
\end{tabular}

Table 3 shows that lower platelet counts are associated with presence of esophageal varices.

Table 4: Esophageal varices and mean platelet count to splenic diameter ratio

\begin{tabular}{lcccc}
\hline $\begin{array}{l}\text { Esoph- } \\
\text { ageal } \\
\text { varices }\end{array}$ & $\begin{array}{c}\text { No of } \\
\text { patients }\end{array}$ & $\begin{array}{c}\text { Mean } \\
\text { platelet } \\
\text { count to } \\
\text { splenic } \\
\text { diameter } \\
\text { ratio }\end{array}$ & $\begin{array}{c}\text { Stand- } \\
\text { ard } \\
\text { deviat- } \\
\text { ion }\end{array}$ & $\begin{array}{c}\text { P } \\
\text { value }\end{array}$ \\
\hline No varix & 12 & 1953.7 & 758.5 & \\
Varices & 68 & 748.2 & 356.8 & $<0.001$ \\
present & & & & \\
\hline
\end{tabular}

Table 4 shows that esophageal varices and mean platelet count to splenic diameter ratio are significantly associated.

Table 5: Using the cut off value of 1150 to predict the presence of esophageal varices

\begin{tabular}{lccc}
\hline $\begin{array}{l}\text { Platelet } \\
\text { count }\end{array}$ & \multicolumn{2}{c}{ Varices } & Total \\
\cline { 2 - 4 } $\begin{array}{l}\text { splenic } \\
\text { diameter } \\
\text { ratio }\end{array}$ & Present & Absent & \\
$<1150$ & $61(89.7 \%)$ & $2(16.7 \%)$ & $63(78.8 \%)$ \\
$\geq 1150$ & $7(10.3 \%)$ & $10(83.3 \%)$ & $17(21.2 \%)$ \\
Total & $68(100 \%)$ & $12(100 \%)$ & $80(100 \%)$ \\
\hline
\end{tabular}


The table 5 shows that using the cut off value of 1150 for platelet count/ splenic diameter ratio has sensitivity of $89 \%$, specificity of $83.3 \%$, positive predictive value of $96.8 \%$ and negative predictive value of $58.8 \%(\mathrm{p}=0.002, \mathrm{CI}=95 \%)$ with accuracy of $89.5 \%$.

\section{DISCUSSION}

Alcoholic cirrhosis is common in Nepal. Most patients in this study were in the $40-49$ age groups. The minimum age was 22 years and the maximum age was 81 years with a standard deviation of 11.4 years and the mean age of 47.2 years and median age of 46 years. In the study conducted in Dharan, Nepal the common age of presentation and symptoms seemed to be similar with a mean age of 49.1 years with standard deviation of 11.3 years and abdominal distension and jaundice being the common symptoms. ${ }^{10}$

This study showed that patients with esophageal varices have low platelet count than the patients without varices. Patients with esophageal varices have mean platelet count of $97235 / \mathrm{mm}^{3}$ with standard deviation of $72001 / \mathrm{mm}^{3}$ as compared to the mean platelet count of $236833 / \mathrm{mm}^{3}$ with standard deviation of $87797 / \mathrm{mm}^{3}$ in patients without varices. This is statistically significant $(\mathrm{p}<0.001, \mathrm{CI}=95 \%)$. This is supported by a prospective study conducted at Kilpauk medical college Chennai analyzed 106 newly diagnosed patients with liver diseases from January 2007 to March 2008. The independent predictor for the presence of varices was platelet count $<150,000 / \mathrm{mm}^{3} .{ }^{11}$ A cross sectional study conducted at Cipto Mangunkusumo Hospital, Indonesia included 47 consecutive cirrhotic patients without history of variceal hemorrhage in detecting noninvasive parameters of esophageal varices who underwent upper GI endoscopy. The study found that the mean platelet count in the group with varices was $101,000 \pm 52,000 / \mathrm{mm}^{3}$, while that of the group without esophageal varices was 161,000 $\pm 62,000 / \mathrm{mm}^{3}$, with $\pm 60,000 / \mathrm{mm}^{3}$ difference in mean value. ${ }^{12}$

Moderate thrombocytopenia is a frequent finding in cirrhosis of the liver and well tolerated in most instances. The pathophysiology of thrombocytopenia in liver disease has long been associated with the concept of hypersplenism, where portal hypertension was thought to cause pooling and sequestration of all corpuscular elements of the blood, predominantly thrombocytes in the enlarged spleen. With the discovery of the lineage-specific cytokine thrombopoeitin (TPO) the missing link between hepatocellular function and thrombopoiesis was found. TPO is predominantly produced by the liver and constitutively expressed by hepatocytes. TPO production in human is dependent on functional liver cell mass and is reduced when liver cell mass is severely damaged. This leads to reduced thrombopoiesis in the bone marrow and consequently to thrombocytopenia in the peripheral blood of patients with advanced-stage liver disease. 13,14 In alcohol related liver disease, ethanol may directly suppress platelet production and folate deficiency, which further impairs production. ${ }^{15}$

In this study mean platelet count to splenic diameter (PC/SD) ratio was found to be associated with presence of esophageal varices. The patients without esophageal varices have mean PC/SD ratio of 1953.7 with standard deviation of 758.5 whereas patients with varices have mean PC/SD of 748.2 with standard deviation of 356.8 . This finding is statistically significant to predict the presence of esophageal varices $(\mathrm{p}<0.001, \mathrm{CI}=95 \%)$.

The result of this study indicates that the $\mathrm{PC} /$ SD ratio with an area under receiver operating characteristic curve of 0.895 [95\% CI (0.773-1.00)] could be a valuable predictor of esophageal varices in portal hypertension patients. The ideal reference point under the curve is 1.00 . In this study a cut off value of 1150 is determined using ROC curve and analyzing the various coordinate points to maximize the difference of sensitivity value and 1-specificity value. This cut off value has the sensitivity of $89.7 \%$, specificity of $83.3 \%$, positive predictive value of $96.8 \%$ and negative predictive value of $58.8 \%(\mathrm{p}=$ $0.002, \mathrm{CI}=95 \%$ ) for the prediction of esophageal varices with predictive accuracy of $89.5 \%$.

\section{CONCLUSION}

The study concludes that platelet count to splenic diameter ratio(PC/SD) with a cut off value of 1150 has sensitivity of $89.7 \%$, specificity of $83.3 \%$, positive predictive value of $96.8 \%$ and negative predictive value of $58.8 \%(\mathrm{p}=0.002, \mathrm{CI}=95 \%)$ with predictive accuracy of $89.5 \%$. The study favored $\mathrm{PC} / \mathrm{SD}$ ratio is a valuable predictor for presence of esophageal varices in patients with portal hypertension.

\section{Limitations of the study}

There were limited numbers of patients in 
the study.

Randomization was not done.

The sonographic findings are operator dependent

Time duration was limited.

Conflict of interest: None

\section{REFERENCES:}

1. Fattovich G, Giustina G, Degos F, Tremolada F, Diodati G, Almasio P, et al. Morbidity and mortality in compensated cirrhosis type $\mathrm{C}$ : a retrospective follow-up study of 384 patients. Gastroenterology. 1997;112(2):463-72.

2. Gentilini P, Laffi G, La Villa G, Romanelli G, Buzzelli G, Casini-Raggi V, et al. Long course and prognostic factors of virus-induced cirrhosis of the liver. American Journal of Gastroenterology. 1997;92(1).

3. Garrison RN, Cryer HM, Howard DA, Polk $\mathrm{Jr}$ H. Clarification of risk factors for abdominal operations in patients with hepatic cirrhosis. Annals of surgery. 1984;199(6):648.

4. Farooqi RJ, Farooqi JI, Ahmad H, Ahmad F, Gul S. Outcome after injection sclerotherapy for esophageal variceal bleeding in patients with liver cirrhosis and COPD. Journal of Postgraduate Medical Institute (Peshawar-Pakistan). 2011;19(1).

5. Mishra A, Shrestha P, Bista N, Bhurtel P, Bhattarai $\mathrm{S}$, Thakali K, et al. Pattern of liver diseases. Journal of Nepal Health Research Council. 2009;7(14):5.

6. Chalasani N, Imperiale TF, Ismail A, Sood G, Carey M, Wilcox CM, et al. Predictors of large esophageal varices in patients with cirrhosis. The American journal of gastroenterology. 1999;94(11):3285-91.

7. Grace ND, Groszmann RJ, Garcia-Tsao G, Burroughs AK, Pagliaro L, Makuch RW, et al. Portal hypertension and variceal bleeding: an AASLD single topic symposium. Hepatology. 1998;28(3):868-80.

8. D’Amico G, Garcia-Pagan JC, Luca A, Bosch J. Hepatic vein pressure gradient reduction and prevention of variceal bleeding in cirrhosis: a systematic review. Gastroenterology.
9. Garcia-Tsao G, Sanyal AJ, Grace ND, Carey W. Prevention and management of gastroesophageal varices and variceal hemorrhage in cirrhosis. Hepatology. 2007;46(3):922-38.

10. Maskey R, Karki P, Ahmed S, Manandhar D. Clinical profile of patients with cirrhosis of liver in a tertiary care hospital, Dharan, Nepal. Nepal Med Coll J. 2011;13(2):115-8.

11. SarangapaniA, ShanmugamC, Kalyanasundaram M, Rangachari B, Thangavelu P, Subbarayan JK. Noninvasive prediction of large esophageal varices in chronic liver disease patients. Saudi Journal of Gastroenterology. 2010;16(1):38.

12. Prihartini J, Lesmana L, Manan C, Gani RA. Detection of esophageal varices in liver cirrhosis using non-invasive parameters. portal. 2005;37(3).

13. Peck-Radosavljevic M. Thrombocytopenia in liver disease. Canadian journal of gastroenterology= Journal canadien de gastroenterologie. 2000;14:60D-6D.

14. Giannini E, Botta F, Borro P, Malfatti F, Fumagalli A, Testa E, et al. Relationship between thrombopoietin serum levels and liver function in patients with chronic liver disease related to hepatitis $\mathrm{C}$ virus infection. The American journal of gastroenterology. 2003;98(11):2516-20.

15. Sallah S, Bobzien W. Bleeding problems in patients with liver disease: ways to manage the many hepatic effects on coagulation. Postgraduate medicine. 1999;106(4):187-95. 